\title{
Random Probability Analysis of Recent 48Ca Experiments
}

M. A. Stoyer, J. B. Patin, J. M. Kenneally, K. J. Moody, D. A. Shaughnessy, N. J. Stoyer, J. F. Wild, P. A. Wilk, V. K. Utyonkov, Yu. Ts. Oganessian

September 30, 2004

The Fourth International Conference on Exotic Nuclei and Atomic Masses

Pine Mountain, GA, United States

September 12, 2004 through September 16, 2004 
This document was prepared as an account of work sponsored by an agency of the United States Government. Neither the United States Government nor the University of California nor any of their employees, makes any warranty, express or implied, or assumes any legal liability or responsibility for the accuracy, completeness, or usefulness of any information, apparatus, product, or process disclosed, or represents that its use would not infringe privately owned rights. Reference herein to any specific commercial product, process, or service by trade name, trademark, manufacturer, or otherwise, does not necessarily constitute or imply its endorsement, recommendation, or favoring by the United States Government or the University of California. The views and opinions of authors expressed herein do not necessarily state or reflect those of the United States Government or the University of California, and shall not be used for advertising or product endorsement purposes. 
EPJ manuscript No.

(will be inserted by the editor)

\title{
Random Probability Analysis of Recent ${ }^{48}$ Ca Experiments
}

\author{
M.A. Stoyer ${ }^{1}$, J.B. Patin ${ }^{1}$, J.M. Kenneally ${ }^{1}$, K.J. Moody ${ }^{1}$, D.A. Shaughnessy ${ }^{1}$, N.J. Stoyer ${ }^{1}$, J.F. Wild ${ }^{1}$, P.A. Wilk ${ }^{1}$, \\ V.K. Utyonkov², and Yu.Ts. Oganessian ${ }^{2}$ a \\ 1 Lawrence Livermore National Laboratory, Livermore, CA 94550 USA \\ 2 Joint Institute for Nuclear Research, RU-141980 Dubna, Moscow Region, Russia
}

Received: February 24, 2005/ Revised version: February 24, 2005

\begin{abstract}
A Monte Carlo random probability analysis developed at LLNL for heavy element research was performed for recent experiments aimed at the synthesis of nuclides with $Z \geq 112$ and $N \geq 170$, to estimate the probability that observed decay chains were a result of a random event. Low probabilities $\left(<10^{-4} \%\right.$ for most decay chains) were found.
\end{abstract}

PACS. 27.90.+b Properties of nuclei $A \geq 220-02$. Mathematical methods in physics

Since 1998, the Dubna-Livermore collaboration has performed extensive and lengthy experiments at the JINR U400 Cyclotron bombarding various actinide targets $\left({ }^{238} \mathrm{U}\right.$, ${ }^{242,244} \mathrm{Pu},{ }^{243} \mathrm{Am},{ }^{245,248} \mathrm{Cm}$, and $\left.{ }^{249} \mathrm{Cf}\right)$ with ${ }^{48} \mathrm{Ca}$ aimed at producing isotopes of elements 112-118[1] (see Fig. 1). The nuclides of interest, called evaporation residues (EVR) are separated from un-reacted beam, transfer products and other background reactions using the Dubna Gas Filled Separator, and are implanted into a position-sensitive $\mathrm{Si}$ detector array. Position-correlated decay events are observed in this detector during the beam-on (or beam-off) periods, which thus provides for a variable background counting rate in the detectors during the $\sim$ month-long experiments. Because of the influence of the closed shells at $N=184$ and $Z=114,120$ or 126 , the nuclides produced typically alpha-decay one or more times, before the decay sequence is terminated by a spontaneous fission (SF). Because of the low statistics involved in these experiments, often just one or two interesting events per month, and the long duration of the runs requiring stable operation of the accelerator and detection equipment, it is extremely important to understand the probability that the observed decay sequence might be merely due to a random event. Some estimates of these random probabilities [2] rely on average counting rates within the detectors or within position pixels defined by the detector position resolution for example, and thus are not able to consider variable backgrounds or counting rates.

A Monte Carlo method for estimating random probabilities was developed for these kind of experiments and is discussed more thoroughly in [3]. This method inserts a

\footnotetext{
a Much of the support for work at LLNL was provided by the U.S. Department of Energy under contract W-7405-Eng-48 and for the work at JINR was through the Russian Federation for Basic Research grant no. 04-02-17186.
}

fission event (could be extended to a random alpha-decay) randomly in time and position into the actual data, and the same search algorithm used to locate decay chains of interest in the experiments searches for correlations with the random event, automatically including fluctuating background effects.

The results of the Monte Carlo random probability calculations are shown in Table 1 . It should be noted that no attempt to eliminate decay chains on the basis of the semiempirical Geiger-Nuttal relationship has been made in this study. Previously, many assumptions, such as which random number generator was used and non-uniform distributions of random fissions, were tested and found to have negligible effect on the calculated random probabilities [3]. Additionally, for the first element 114 experiment, the random probabilities calculated using this method were compared with other methods and generally found to be higher (thus more conservative). The search algorithm used in this study does not take into account decay chains with missing alpha-decays, decay chains with alpha-events in the side detector only (ie., no position information), or decay chains that span more than one file or run, which is typically on the order of a few hours. The element 115 $\mathrm{SF}$ with a half life of around $30 \mathrm{~h}$ was handled differently. Generally, the parameters for the search algorithm were: EVR energy between 7 and $14 \mathrm{MeV}$, event positions \pm 2 $\mathrm{mm}$, alpha energies within a $1-2 \mathrm{MeV}$ window around the observed alpha-decay energies, SF energy $>130 \mathrm{MeV}$, and maximum correlation times variable depending upon the type of correlation (EVR- $\alpha, \alpha-\alpha$, or $\alpha$-SF). While counting rates vary depending upon the particular experiment, beam rates, detector positions and target thicknesses, typical counting rates within the $\pm 2 \mathrm{~mm}$ position resolution for EVR-like events, for alpha-like events (beam on/beam off $)$, and SF-like events are $\sim 3 \mathrm{~h}^{-1},\left(\sim 1.5 \mathrm{~h}^{-1} / \sim 0.7\right.$ 


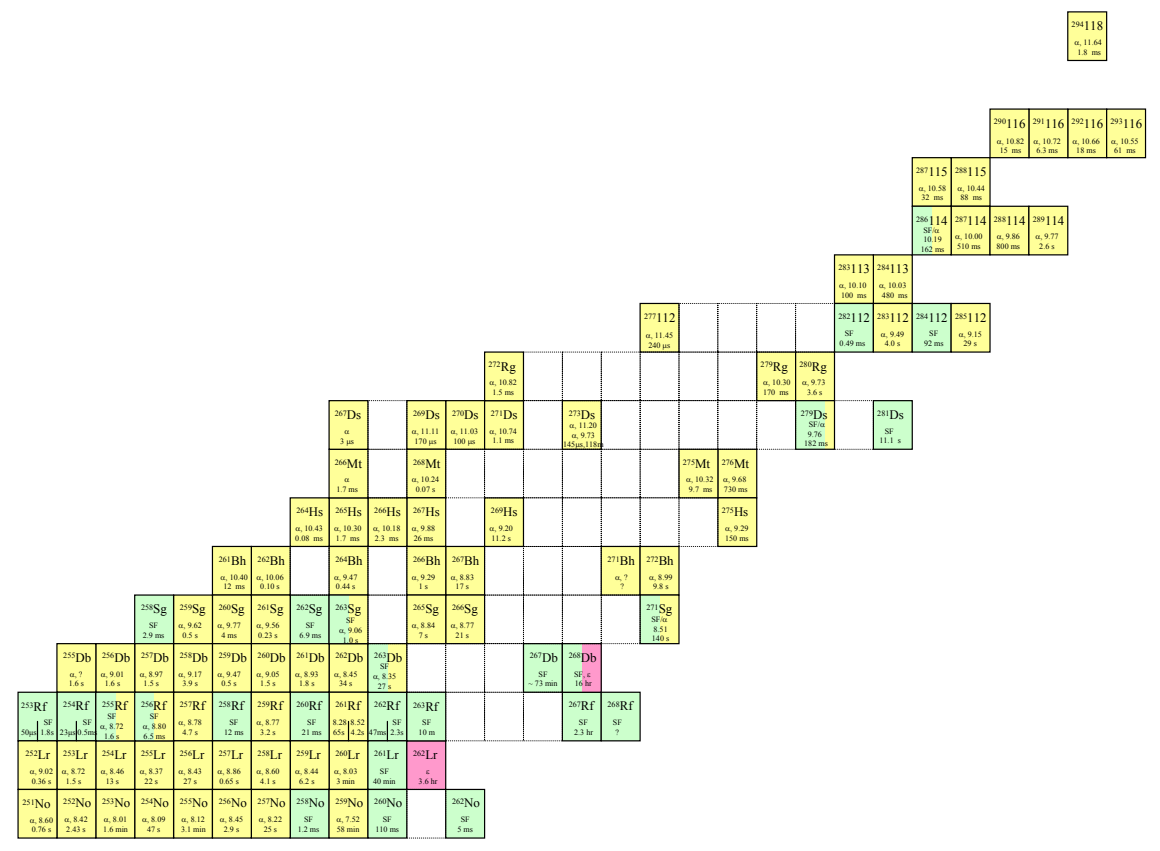

Fig. 1. Upper end of the Chart of Nuclides showing the isotopes synthesized within the last 6 years and their nuclear properties.

Table 1. Calculated probabilities that an observed decay sequence is due to random events for recent heavy element reactions. Note that because the overall decay chain duration is short for many of these isotopes, more random fissions may be required to ensure convergence of the method. These results are for $10-100$ million random fissions. In some cases, random probabilities are presented for shorter decay chains than actually observed (ie., decay chains with fewer alpha-decays), which already results in small probabilities that the observed decay chains are a result of randomness. Additionally, random probabilities for EVR-SF events were also calculated for all cases (not shown).

\begin{tabular}{lll}
\hline $\begin{array}{l}\text { Initial isotope } \\
\text { of decay chain }\end{array}$ & $\begin{array}{l}\text { Production Reaction } \\
\left({ }^{48} \mathrm{Ca}+\ldots\right)\end{array}$ & $\begin{array}{l}\text { Random Probability } \\
(\%)\end{array}$ \\
\hline${ }^{294} 118$ & ${ }^{249} \mathrm{Cf}$ & $1.0 \times 10^{-5 *}$ \\
${ }^{291} 116$ & ${ }^{245} \mathrm{Cm}$ & $5.0 \times 10^{-6 *}$ \\
${ }^{290} 116$ & ${ }^{245} \mathrm{Cm}$ & $2.0 \times 10^{-4 *}$ \\
${ }^{288} 115$ & ${ }^{243} \mathrm{Am}$ & $1.5 \times 10^{-4 *}$ \\
${ }^{289} 114$ & ${ }^{244} \mathrm{Pu}$ & 0.172 \\
${ }^{288} 114$ & ${ }^{244} \mathrm{Pu}$ & $8.6 \times 10^{-4}$ \\
${ }^{287} 114$ & ${ }^{244} \mathrm{Pu}$ & $8.5 \times 10^{-5}$ \\
${ }^{287} 114$ & ${ }^{242} \mathrm{Pu}$ & $4.1 \times 10^{-4}$ \\
${ }^{286} 114$ & ${ }^{242} \mathrm{Pu}$ & $6.0 \times 10^{-5}$ \\
\hline
\end{tabular}

${ }^{*}$ For decay chain with fewer alpha-decays than observed.

$\mathrm{h}^{-1}$ ), and $\sim 0.01 \mathrm{~h}^{-1}$, respectively. For most chains, the probability that the decay chain is due to a random event is in the range of $10^{-4}-10^{-5 \%}$, which is in general higher (more conservative) than other methods. The distribution of time differences between a randomly inserted fission event and the nearest preceeding EVR is shown in Fig. 2 for the ${ }^{48} \mathrm{Ca}+{ }^{245} \mathrm{Cm}$ experiment. Note the location of the actual observed decay chains, much earlier in time than what would be the average of the distribution of random events. The position of the centroid can be estimated from the EVR-like counting rate for the ${ }^{48} \mathrm{Ca}+{ }^{245} \mathrm{Cm}$ experiment of $\sim 0.0039 \mathrm{~s}^{-1}$. The time difference between EVRs in a detector position, averaged over the whole detector, is $\sim 300 \mathrm{~s}-$ half this is the everage time interval between an EVR and a randomly inserted fission, namely $\sim 150$ s, which is consistent with the $244 \mathrm{~s}$ obtained from the Monte Carlo method properly taking into account all deviations from average.

\section{References}

1. Yu. Ts. Oganessian, et al., Phys. Rev. Lett. 83, (1999) 3154; Yu. Ts. Oganessian, et al., Phys. Rev. C62, (2000) 041604(R); Yu. Ts. Oganessian, et al., Phys. Rev. C69, (2004) 054607; and Yu. Ts. Oganessian, et al., Phys. Rev. C69, (2004) 021601.

2. K.-H. Schmidt, et al., Z. Phys. A316, (1984) 19; Yu. A. Lazarev, et al., Phys. Rev. C54, (1996) 620.

3. N.J. Stoyer, et al., Nucl. Inst. Methods Phys. Res. A455, (2000) 433.

This work was performed under the auspices of the U.S. Department of Energy by University of California, Lawrence Livermore National Laboratory under contract W-7405-Eng-48. 


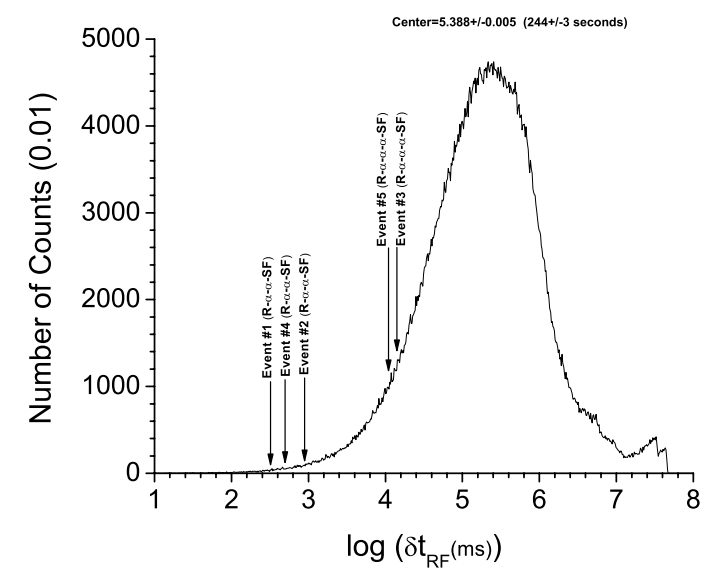

Fig. 2. Average time intervals between an implanted EVR and a randomly inserted fission for the ${ }^{48} \mathrm{Ca}+{ }^{245} \mathrm{Cm}$ experiment and 1 million random fissions. 